Western University Scholarship@Western

Electrical and Computer Engineering Publications Electrical and Computer Engineering Department

$1-2012$

\title{
Soft Skills Requirements in Software Development Jobs: A Cross-Cultural Empirical Study
}

Faheem Amed

Thompson River University, fahmed@tru.ca

Luiz Fernando Capretz

University of Western Ontario, lcapretz@uwo.ca

Salah Bouktif

United Arab Emirates University, s.bouktif@uaeu.ac.ae

Piers Campbell

United Arab Emirates University, p.campbell@uaeu.ac.ae

Follow this and additional works at: https://ir.lib.uwo.ca/electricalpub

Part of the Software Engineering Commons

Citation of this paper:

DBLP BibTeX Record 'journals/jsit/AhmedCBC12' @article\{DBLP:journals/jsit/AhmedCBC12, author $=\{$ Faheem Ahmed and Luiz Fernando Capretz and Salah Bouktif and Piers R. J. Campbell $\}$, title $=\{$ Soft Skills Requirements in Software Development Jobs: A Cross Cultural Empirical Study $\}$, journal $=\{\mathrm{J}$. Systems and IT $\}$, volume $=\{14\}$, number $=\{1\}$, year $=\{2012\}$, pages $=\{58-81\}$, ee $=$ $\{$ http://dx.doi.org/10.1108/13287261211221137\}, bibsource $=\{$ DBLP, http://dblp.uni-trier.de $\}$ 


\title{
Soft Skills Requirements in Software Development Jobs: A Cross-Cultural Empirical Study
}

\begin{abstract}
Different parts of the world have different cultures and culture has an impact on the way people perceive, plan and execute any assignment. The success and failure stories of software projects reveal that human factors are one of the significantly important issues. Psychological theories assert that people have different personality traits and these personality traits are pigeonholed by soft skills or emotional intelligence. Most of the studies carried out on human factor in software engineering concentrate primarily on personality traits. However, soft skills which largely determine personality traits have been given comparatively little attention by researchers from software engineering community. The main objective of this work is to find out whether employers' soft skills requirements, as advertised in job postings, within different roles of software development are similar across different cultures. We used a dataset of 500 job descriptions from four different regions of the world in this study. We found that in the cases of designer, programmer and tester substantial similarity exits for the requirements of soft skills whereas only in case of system analyst dissimilarity is present across different cultures.
\end{abstract}

Keywords: Soft Skill, Software Development, Empirical Software Engineering, Diversity in Software Engineering, Human Factors in Software Engineering.

\section{INTRODUCTION}

Software is a by-product of human activities, which often include problem solving capabilities, cognitive aspects, and social interaction. Human beings, however, are more complicated and less predictable than computers and therefore the complexity of the human personality gives rise to intricate dynamics which exist during software development and that cannot be ignored, but which are frequently overlooked. When someone accepts the premise that awareness of psychological dimensions within oneself and human factors within one's work environment increase the software engineer's productivity, we must then wonder which psychological traits and social skills would be significant and therefore worth investigating further. It would be impossible to deny that the production of any piece of software involves a human element, and therefore it is equally intuitive that better results can be achieved if people with particular social skills are assigned to phases of a project to which they are best suited, based on their personality composition. 
The overall software development process can be characterized as set of activities comprising system analysis, design, coding, and testing. Logically these are separate tasks which when coupled together enable software construction and operation. Each of these tasks also requires that the individuals involved have a particular set of skills which may not necessarily be common across all activities. The psychological hypothesis that not everyone can perform all tasks effectively reveals that personality traits play a critical role in the performance of people executing the same task. Although the field of software psychology was fashioned many decades ago (Shneiderman 1980), it has been neglected over recent past years due to the complexity of human nature and difficulty in effectively assessing its impact on software development. In our society today, the software industry has become a major employer and the specialties within software engineering are as diverse as those in any other profession. Software engineering comprises stages in separate and distinct phases including system analysis, design, programming, testing, and maintenance.

Software engineering job descriptions (either on- or off-line) normally divide required skills into two broad categories; "hard skills" and "soft skills". Whilst hard skills refer to the technical knowledge and abilities that an individual should have to carry out the tasks associated with the position. Soft skills grew from the psychology domain and pertain to a broad range of characteristics involving personality types, social interaction abilities, communication, and personal habits. In order to perform the job successfully, an employee should not only master specific technical skills, but he or she should possess other important soft skills, e.g. team work ability, a work ethic, and communication skills (Stolte and Munjanganja 2008). Soft skills are the personal individuality that has a major impact on the behavior of a person during their interaction with others in a work environment. In the collaborative environment of software development the possession and use of soft skills enhances the likelihood of an individual's success and contributes positively towards the common goal of the project. As companies rely more heavily on project teams and expect software engineers to partner with their customers, opportunities for conflicts and misunderstandings abound. Soft skills are usually overlooked in software engineering because the relationship between software engineering and soft skills is extremely complex to investigate.

\section{A. Research Motivations \& Question}

Specific studies concerning soft skills and software engineering have been sporadic and often incidental, which highlights the initial motivation of this work. Researchers from software engineering explored the area of human factors solely in terms of personality traits or types and no concrete work 
has been reported in the area of soft skills in general and specifically their demand as a part of job requirement sets in diverse cultures. Therefore it would appear to be a suitable juncture in the evolution of software engineering to address the specific psychological factors as applied to the work of various software industry professionals. The reason for addressing these human factors is largely the recognition that software engineers could benefit from greater awareness of themselves and others in order to develop their "soft skills", which in turn may positively influence their work. A fundamental motivation of this study is to find out the answer of the following research question from the perspective of the software industry:

Research Question (RQ): Are employers'soft skills requirements, as advertised in job postings, within different roles of software development similar across different cultures of the world?

In this study we consider nine soft skills which include communication skills, interpersonal skills, analytical and problem solving skills, team player, organizational skills, fast learner, ability to work independently, innovative and open and adaptable to changes. We found these nine soft skills most commonly used in the description of job advertisements which highlights the reason for their inclusion in this study. In order to find out the answer to the research question (RQ) as stated above we further refine here the RQ into sub-RQs for the purpose of better understanding and segregation of individual roles:

RQ-1 = Are employers' soft skills requirements, as advertised in the job postings of system analyst, similar across different cultures of the world?

RQ-2 = Are employers' soft skills requirements, as advertised in the job postings of software designer similar across different cultures of the world?

RQ-3 = Are employers' soft skills requirements, as advertised in the job postings of computer programmer, similar across different cultures of the world?

RQ-4 = Are employers' soft skills requirements, as advertised in the job postings of software tester, similar across different cultures of the world?

\section{LiterATURE SURVEY}

Developing high quality software has always been an important priority in the software industry. However recruiting and retaining high quality software engineering professionals has never been easy 
for management similar to other industry. Human factors in software engineering have different dimensions and studies have been performed from different perspectives. For example, these perspectives could be the investigation of human factors in different phases of software life cycle, or the effect of team work in software development, or how a personality profile can suit a particular task, for example code review? Few studies have investigated the relationship between human soft skills and the software life cycle phases. We divided the literature survey into three sub-sections; the first sub-section highlights the work carried in the area of human factor and software engineering which mainly revolves around personality traits; the second sub-section describes the work related to the soft skills and software development and highlights the absence of related work in the field of software engineering; the final sub-section provides information the definition of culture and how it is related to software development.

\section{A. Literature Survey of Human Factor in Software Engineering}

Although it is important to understand the characteristics and personality traits of people involved in software development, little attention has been paid to these aspects (Wynekoop and Walz 2000). Karn and Cowling (2005) investigated the effects of different personality types on the working of software engineering teams. The results of the study indicated that certain personality types were more inclined to certain roles. Using the 16PF test (Russell and Karol 1994), Acuna et al. (2006) measured the correspondence between individual capabilities, such as intrapersonal, organizational, interpersonal, management, and software roles, including team leader, quality manager, requirements engineer, designer, programmer, maintainer, tester, and configuration manager. Feldt et al. (2008) evaluated the personality of 47 software professionals using the IPIP 50-item five-factor personality test (Buchanan et al. 2005). After extensive statistical analyses, they found that there are multiple and significant correlations between personality factors and software engineering, and they concluded that individual differences in personality can explain and predict how judgments are made and how decisions are evaluated in software development projects. Hannay et al. (2010) reported the impact of the Big Five (Goldberg 1990) personality traits on the performance of pair programmers together with the impact of expertise and task complexity. Furthermore, Shneiderman (1980) reported that some programmers performed as much as ten times better than other programmers with similar backgrounds. Walz and Wynekoop (1997) derived a methodology for identifying the traits and characteristics of top performing software developers. Turley and Bieman (1995) also seek to identify the attributes that differentiate exceptional and non-exceptional software engineers and map them to the Myers-Briggs Type Indicator (MBTI) scale. 
Bishop-Clark (1995) investigated the relationship between cognitive aspects, personality traits and computer programming. There is clear evidence that personality preferences have great impact on motivation, quality of work, and retention in the field of software engineering (Kaluzniacky 2004). The eight MBTI scales are Extroversion (E), Introversion (I), Sensing (S), Intuition (N), Thinking (T), Feeling (F), Judging (J) and Perceiving (P). Hardiman (1997) observed that the majority of good programmers were ISTJ, INTJ, ESTJ, ENTJ, ISFJ, or ENTP; in brief, they are mostly NTs and SJs. Capretz (2003) has investigated the profile of a group of 100 software engineers and the study showed that ISTJ, ISTP, ESTP and ESTJ orientations compose over 50\% of the sample and are therefore significantly over-represented, whereas the INFJ, ESFP and ENFJ groups are all under-represented. Teague (1998) tried to map the MBTI dimensions into three major subtasks of computing: system analysis, system design, and programming. More recently, Capretz and Ahmed (2010) mapped some opposing psychological traits, such as extroversion-introversion, sensing-intuition, thinking-feeling, and judging-perceiving, to the main stages of a software development life cycle. Software is developed by people, used by people, and supports people's work. As such, human characteristics, behavior, and cooperation are central to practical software development (DeSouza et al. 2009).

\section{B. Literature Survey of Soft Skills}

The advertisement of jobs in the area of software development generally divides the skill requirements into two categories of "hard skills" and "soft skills". Technical or hard skills are defined as "those skills acquired through training and education or learned on the job and are specific to each work setting," while soft skills are defined as "the cluster of personality traits, social graces, language skills, friendliness, and optimism that mark each one of us to varying degrees" (Tech Directors, 2003). Hard skills are the technical requirements and knowledge a person should have to carry out a task. This includes the theoretical foundations and practical exposure an individual should have to successfully execute the planned task. Even though soft skills are the psychological phenomena which cover the personality types, social interaction abilities, communication, and personal habits, people believe that soft skills complement hard skills. Soft skills refer to the cluster of personality traits and attitudes that drives one's behavior (Roan and Whitehouse 2007). Soft skills indirectly define the personality traits, ability to have social interaction, and eagerness which individuals acquire as they grow and mature. Other classical sets of soft skills are active listening, negotiating, conflict resolution, problem solving, reflection, critical thinking, ethics, and leadership skills (Dash 2001; Gorman 2000; Isaacs 1998; Schulz 1998). Soft skills complement the technical skills requirements of a job (Lewis et al. 2008). 
According to Goleman (1995) the possession and use of soft skills contributes more to an individual's ultimate success or failure than technical skills or intelligence. Bolton (1986) reported that 80 percent of individuals who fail at work, do not fail due to their lack of technical skills but rather because of their inability to relate well with others. A lack of soft skills is more likely to get an individual's employment terminated than a lack of cognitive or technological skills (Behm 2003). As software development is a team-based endeavor, it is necessary to determine which soft skills are required in which phase of software development. These skills vary depending upon the needs and characteristics of the software project and domain of application, but there are some skills that may be common to a specific phase of software development. McGee (1996) reported, for example, that $68 \%$ of CIOs said that "soft skills," i.e., skills of a non-technical nature such as communication and team building, are more important today than five years ago. Young and Lee (1996), and Van Slyke et al. (1998) found that employers tend to rate non-technical skills higher than technical skills.

Cappel (2002) concluded that non-technical skills such as oral and written communication, problem solving, and the ability to learn apply to virtually all IS jobs. According to the survey of Green (1989) the job of systems analyst considers behavioral skills such as diplomacy, politics, and sales more important, while users consider technical skills such as programming to be more important. Khan and Kukalis (1990) concluded that both hard and soft skills are important, but the hard skills are considered less important than soft skills. Leitheiser (1992) found that people-oriented and organizational skills were more important than technical skills. Trauth et al. (1993) examined the perceived importance of skills for information systems professionals and their academic preparation. Leitheiser's (1992) survey of information systems managers ranked interpersonal communication skills as most important. One critique against Leitheiser's (1992) survey would be that information systems managers in many cases do not have a technical background and that might be a threat to the validity concerning their findings as those managers in many cases look to softer skills as they themselves do not possess high levels of technical skills. Wade and Parent (2001) found that analysts perceive organizational skill as most important, whereas Green (1989) found that behavioral skills, such as diplomacy, sales and politics are most important. Litecky et al. (2004) presented an overview of studies dealing with the paradox of soft skills versus technical skills in hiring. On the contrary some surveys such as (Green 1989; Byrd and Turner 2004; Lau et al. 1997) concluded that technical skills are most important in managing information systems.

\section{What is Culture?}

Anthropologists, psychologists, sociologists, and organizational theorists provide many definitions of culture and some of these definitions are specific to a work environment. According to Samovar and 
Porter (1995) culture is the deposit of knowledge, experience, beliefs, values, attitudes, meanings, hierarchies, religion, notions of time, roles, spatial relations, concepts of the universe, and material objects and possessions acquired by a group of people in the course of generations through individual and group striving. Fiske et al. (1998) concluded that culture also molds the way people think: what their motivations are, how they categorize things, what inference and decision procedures they use, and the basis on which they evaluate themselves. Hofstede (1994) called culture the "software of the mind" because much like an operating system in a computer it provides us with essential code by which we make sense of the world. Olson and Olson (2003) found that there are multiple kinds of culture: national, regional, occupational, organizational, avocational, and generational and any of these might have important effects. There has been a significant volume of research in the area of social sciences to elaborate the difference among cultures. For example, Hofstede (1994) identified five factors to show the difference of cultures such as revering hierarchy, individualism versus collectivism, task- or relationship-focused, risk avoidance, and long-term orientation in a working environment. Whereas Hall (1960) identified space, material goods, friendship, time, and agreement as important factors in classification of cultures. Faure and Rubin (1993) described culture as a set of shared and enduring meanings, values and beliefs that characterize national, ethnic or other groups and orient their behavior. Harrison et al. (1990) highlighted the need for research on the impact of national and crosscultural issues in case of software development. Ein Dor et al. (1992) proposed some cultural variables that affect information systems development. Shore and Venkatachalam (1995) elaborate the influence of national cultural factors on the approaches to parts of the systems development lifecycle.

The soft skills take influence from culture, for example Olson and Olson (2003) mention that in the case of United States and Netherlands individualism is very high whereas in the case of China, West Africa and Indonesia it is more collective. This means that China, West Africa and Indonesia are more team oriented cultures. In the case of ability to work independently, Olson and Olson (2003) point out that Japan, Germany and USA are very high on task focus whereas France, Russia and the Netherlands has a quality of life focus. This means that the ability to work independently is influenced by the quality of life in the case of France, Russia and the Netherlands. Similarly in the case of open and adoptable to changes, Olson and Olson (2003) found that the USA, India and Hong Kong are more flexible in handling ambiguity. In the USA deadlines are very strictly observed and are more organized in a work setting, whereas other cultures are less strict in managing time issues and delay is a common phenomenon in their daily life as well. In some cultures, like the United States, friends are transitory; people make and lose them frequently, whilst in other cultures, such as France, friendships and 
business relationships take a long time to develop, and people prefer to do business with those they know (Olson and Olson 2003).

\section{SURVEY SETUP \& DATA}

Surveys, experiments, metrics, case studies and field studies are examples of empirical methods used to investigate both software engineering processes and products (Singer and Vinson 2002). In this survey of the software job market we analyzed the soft skills required by the software industry for various titles of software development jobs. We collected data concerning nine soft skills which includes communication skills, interpersonal skills, analytical and problem solving skills, team player, organizational skills, fast learner, ability to work independently, innovative and open and adaptable to changes. In order to better understand the usage and significance of these soft skills we provide here some elaboration of these concepts.

Communication skills are the set of skills that enables a person to convey information so that it is received and understood (Kushal and Ahuja 2009). The term interpersonal skill refers to the person's ability to behave in ways that increase the probability of achieving the desired outcomes. This means that it is a goal-directed behavior of individual used in face-to-face interactions in order to bring about a desired state of affairs (Hayes 2002). Analytical skill is the ability to break a situation down into its component parts, recognize what needs to be done and plan a suitable course of action in a step-by-step way (Parkinson 2008). Problem solving skill is the ability to evaluate a situation and to identify an appropriate solution that meets the customers' needs (Parkinson 2008). Innovative is the ability to produce or propose imaginative and practical solutions to business problems (Parkinson 2008). Team player refers to an individual who is good at working closely with other people (Parcon 2007). Organizational skill is the ability of an individual to assess and prioritize tasks and ensure that they are completed in a timely manner (Beard et al. 2009). Open and adaptable to change reflects the personality of an individual to accept changes in the carrying out of tasks without showing resistance. An employee can be defined as a fast learner if they are able to adapt to new tasks, roles or challenges effectively and with ease (Goleman 1998). The ability to work independently narrates the individual's capability to operate with a reduced level of supervision in order to plan and successfully complete tasks independently (Beard et al. 2009). 


\section{A. Data Collection Procedures \& Description}

The survey consists of 500 jobs advertised across four major regions of the world i.e., North America, Europe, Australia and Asia. In this survey study we visited some of the leading online job seeking portals such as workopolis.ca (North America), eurojobs.com (Europe), monsterindia.com (Asia), and seek.com.au (Australia). It is important to mention here that we visited manually each of the above mentioned online job portals during the period October 2009 to January 2010. No specific consideration was given to the selection of timing for the data collection the choice was simply random. We examined jobs advertised under the exact and related titles of "system analyst", "software designer", “computer programmer", and "software tester". The examples of related titles for computer programmer are such as "Software Developer", "Coder", and "Application Developer". Similarly in case of system analyst some of the related titles were "Business Analyst", "Requirements Analyst", "Technical Analyst", and "Application Analyst". In the case of software tester they were "Application Tester", "Quality Assurance \& Tester", "System Tester", and "Web Tester". While for software designer we also considered the titles of "Software Architect", "Application Designer", and "Solution Architect". It is also important to mention here that when we visited a job page the inclusion of the job post in the study dataset was dependant on the categorical presence of at least one of the above mentioned soft skills in the job posting. Therefore we looked specifically for the key words which related to the soft skills. If we did not find any match then we skipped the job and moved on the next advertisement sequentially. We did not keep a record of those job advertisements that we visited which were found to have no requirement for the selected soft skills. We consider this as one of the limitations of this study and further acknowledged this in a later section of this paper. Figure 1 illustrates the geographical distribution of the survey data. The geographical distribution of the dataset covers 31\% (North America), 26\% (Europe), 23\% (Asia) and 20\% (Australia). Figure 1 also illustrates the job classifications of the survey data. The total dataset of 500 jobs covers $23 \%$ (System Analysts), $21 \%$ (Software Designer), 28\% (Computer Programmer) and 28\% (Software Tester). Figure 2 illustrates the summary of the data collected for this survey with respect to geographical region (North America, Europe, Asia, and Australia) and job category (system analysts, software designer, computer programmer and software tester). We used a three point scale of "High Demand (> 66\%)", "Moderate Demand $(>33 \%$ and $\leq 66)$ ", and "Low Demand $(\leq 33 \%)$ to present linguistically the requirement of soft skills in software industry. 

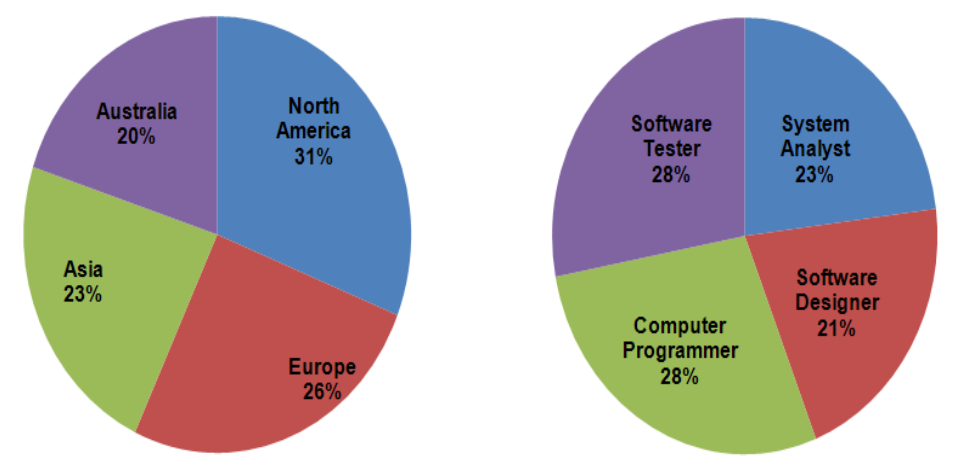

Figure 1: Geographical Distribution \& Job Classification of the Survey Data

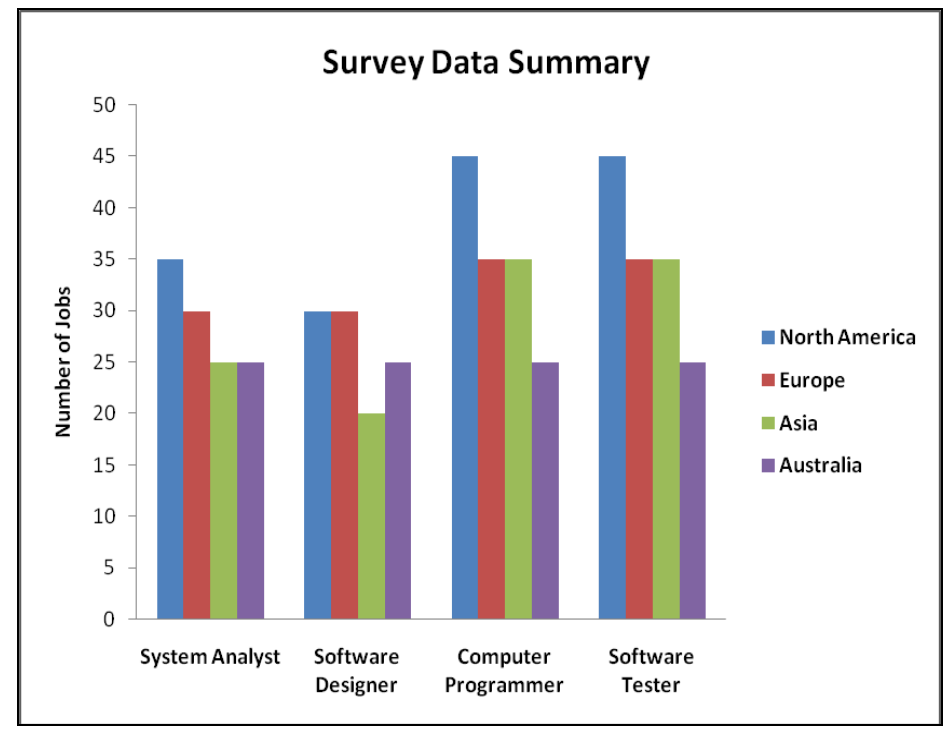

Figure 2: Data Summary of the Survey Geographical \& Job Classification

\section{1) Hypotheses \& Testing Techniques}

In order to empirically investigate the answers of the research questions RQ-1 to RQ-4 we hypothesize the following:

H-1: Employers' soft skills requirements, as advertised in job postings of system analyst are similar across different cultures of the world.

H-2: Employers' soft skills requirements, as advertised in job postings of software designer are similar across different cultures of the world.

H-3: Employers' soft skills requirements, as advertised in job postings of computer programmer are similar across different cultures of the world. 
H-4: Employers' soft skills requirements, as advertised in job postings of software tester are similar across different cultures of the world.

We used the Kendall coefficient of concordance $(W)$ (van Eye and Mun 2005) and Kappa statistics (Cohen 1960) to assess agreement or similarity in the soft skills requirements as advertised in the job postings and to test the significance of the hypotheses H-1 to H4. Cohen's Kappa statistic is a popular measure for measuring the degree of similarity (or agreement) in two samples and extensions to Cohen's Kappa measure have been proposed for more than two samples (Unnikrishnan and Hebert 2005). Kendall's coefficient of concordance $(W)$ is a measure of the agreement among several $(p)$ judges who are assessing a given set of $n$ objects and depending on the application field, the "judges" can be variables, characters, and so on (Legendre 2005 ). The Kendall coefficient of concordance $(W)$ is often preferred to evaluate inter-rater agreement in comparison to Cohen's Kappa (Cohen 1960) in case of ordinal data (van Eye and Mun 2005). " $W$ " is an index of the divergence of the actual agreement shown in the data from the possible perfect agreement. Values of Kendall's $W$ and Kappa coefficient can range from 0 to 1 , with 0 indicating perfect disagreement or dissimilarity, and 1 indicating perfect agreement (Landis and Koch 1977) or similarity. Altman (1991) and Fleiss (1981) provided interpretation of Kappa values shown in Table-I. The result of the statistical calculations for the Kendall coefficient of concordance $(W)$ and Kappa statistics are reported in Table-II and we sued Table-I to interpret the results.

Table I: Interpretation of Kappa Vlaues

\begin{tabular}{|l|l|}
\hline \multicolumn{1}{|c|}{ Altman Kappa Benchmark } & \multicolumn{1}{c|}{ Fleiss Kappa Benchmark } \\
\hline & \\
<0.20 Poor & $<0.40$ Poor \\
$0.21-0.40$ Fair & $0.40-0.75$ Intermediate to Good \\
$0.41-0.60$ Moderate & $>0.75$ Excellent \\
$0.61-0.80$ Good & \\
$0.81-1.00$ Very Good & \\
& \\
\hline
\end{tabular}

Table-II: Hypotheses Testing of Similarity

\begin{tabular}{|c|c|c|c|c|}
\hline \multirow[t]{2}{*}{ Job Role } & \multicolumn{2}{|c|}{ Kendall Statistics } & \multicolumn{2}{|c|}{ Kappa Statistics } \\
\hline & $\begin{array}{c}\text { Kendall's } \\
\text { Coefficient } \\
\text { Of Concordance } \\
(\mathrm{W}) \\
\end{array}$ & $\chi^{2}$ & Kappa Coefficient & $\mathrm{Z}$ \\
\hline System Analyst & 0.40 & $12.54 * * *$ & 0.39 & $3.97 *$ \\
\hline Software Designer & 0.92 & $29.64 *$ & 0.79 & $7.90^{*}$ \\
\hline Computer Programmer & 0.57 & $18.35 * *$ & 0.62 & $6.23 *$ \\
\hline Software Tester & 0.83 & $26.62 *$ & 0.68 & $6.57 *$ \\
\hline
\end{tabular}




\section{SURVEY RESULTS \& Discussion}

The results of this investigation will be discussed separately based on the role performed by a software engineer such as system analyst, designer, programmer, and tester.

\section{A. System Analyst}

\section{1) Descriptive Statistics \& Hypothesis Testing}

In the collection of 115 system analyst opportunities from North America, Europe, Asia and Australia, all four geographical regions of this study show a high demand for communication skills, including North America (100\%), Europe (83\%), Asia (96\%) and Australia (88\%). In case of interpersonal skills only Asia (44\%) shows a moderate demand whereas all other regions, North America (31\%), Europe (20\%) and Australia (12\%) show low demand. Analytical and problem solving skills are in high demand in North America (94\%) and Australia (68\%) and in moderate demand at Asia (64\%) and Europe (46\%). Organizational skills are in moderate demand at North America (65\%) and Asia (40\%) whereas they are in low demand in Europe (20\%), and Australia (16\%). The skill of being a fast learner is given little attention in all four geographical regions and is generally in low demand, North America (17\%), Europe (3\%), Australia (8\%), and Asia (12\%). Team player skills are in high demand in North America (77\%), Europe (66\%), and Asia (68\%), while this skill is in moderate demand in Australia (48\%). The work independently skill is in moderate demand in the North American job market (51\%) while the remaining three regions consider this as a low demand skill, Europe (20\%), Australia (12\%) and Asia (20\%). Innovative and creative thinking ability is in low demand in North America (8\%), Europe (6\%), Australia (12\%), and Asia (0\%). Open and adoptable to changes is only moderately in demand in the North American job market (42\%) whereas the rest of the regions are not paying much attention to this skill in job requirements, Europe (13\%), Australia (8\%), and Asia (8\%). Figure 3 summarizes the survey results. The hypothesis H-1 was tested using the Kendall coefficient of concordance $(W)$ and Kappa statistics and the results are reported in Table-II. The hypothesis is not accepted based on chi-square value of 12.54 and Kendall coefficient of concordance 0.40 was not significant at $\mathrm{P}<0.05$. The Kappa statistics also further support the rejection of hypothesis H-1 (Kappa coefficient: 0.39, Z: 3.97, P < 0.01) because of the low value of the Kappa coefficient according to interpretation of Kappa presented in Table-I. Therefore, we conclude that employers' soft skills requirements, as advertised in job postings of system analyst are not similar across different cultures of the world. 


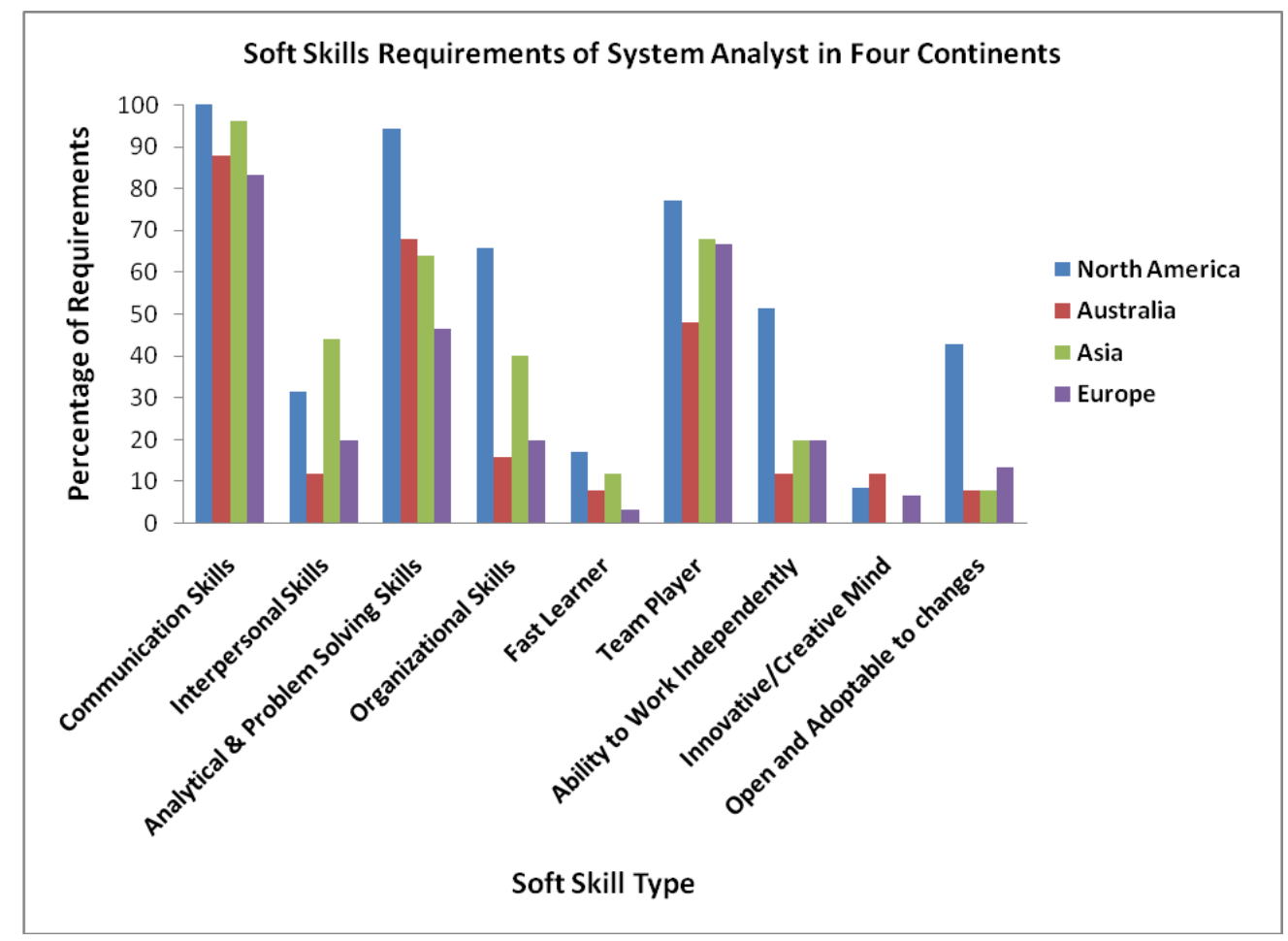

Figure 3: Soft Skills Qualificatons of System Analyst

\section{2) Result Discussion}

The descriptive statistics and statistical tests for the significance of hypothesis $\mathrm{H}-1$ provides us support to conclude the answer of RQ-1, that there is no similarity in soft skills requirements as advertised in the job descriptions of systems analyst across different cultures. The descriptive statistics also show that only in cases of communication skills, being a fast learner and innovative, does similarity in requirements exist and remaining six skills has varying requirements across different cultures. The broader job description of a system analyst is a role that requires the identification of high-level components in a real-world application and decomposition of the software system (Kendall 1992). The analysis shows that the North American job market considers communication, analytical and problem solving, and team player skills to be in high demand while the ability to work independently, open and adoptable to changes and organizational skills are in moderate demand. Whereas interpersonal skills, fast learner and innovative and creative mind are in low demand at the North American market. The Australian job market exhibits a high demand for communication and analytical and problem solving skills while team player skills are in moderate demand. On the other hand the remaining six soft skills under this survey such as ability to work independently, open and adoptable to changes, organizational skills, interpersonal skills, fast learner and innovative and creative mind are in low demand. Asian job market also weights communication and team player in high 
demand whereas analytical and problem solving, organizational skills and interpersonal skills are in moderate demand. Fast learner and innovative and creative mind, ability to work independently, and open and adoptable to changes skills are in low demand in the Asian software industry. In the case of European software industry communication and team player skills are in high demand and analytical and problem solving skills are in moderate demand. While fast learner and innovative and creative mind, ability to work independently, and open and adoptable to changes, organizational skills, and interpersonal skills are in low demand.

\section{B. Software Designer}

\section{1) Descriptive Statistics \& Hypothesis Testing}

We collected data for 105 software designer roles from the opportunities advertised in the job market and analysis shows that in case of communication skills all four geographical regions included in this study demonstrated a high demand, with values of, North America (96\%), Europe (86\%), Asia (95\%) and Australia (92\%). In case of interpersonal skills all four geographical regions of this study also shows a high demand such as North America (93\%), Europe (83\%), Asia (95\%) and Australia (100\%). Analytical and problem solving skills are in moderate demand in North America (46\%), Asia (35\%) and Europe (43\%) while in low demand in Australia (32\%). Organizational skills are in low demand in all four geographical regions North America (26\%), Europe (10\%), Australia (8\%), and Asia (20\%). The skill of fast learner is not being given much attention in any of the four geographical regions and is in low demand, only in North America (10\%) was it found to be given some consideration while we did not find any job advertisement describing this skill as a requirement in European, Australia and Asia. Team player skills are in moderate demand in North America (66\%), Europe (53\%), and Asia (40\%), whereas in Australia (32\%) it is in low demand. The skill to work independently is in low demand in all four regions of North America (20\%), Australia (12\%) and Asia (5\%) whereas we did not find any job advertisement describing this skill as a requirement in Europe. Innovative and creative thinking ability is in low demand in North America (6\%), Europe (10\%), Australia (0\%), and Asia (5\%). Open and adoptable to changes was found to be in low in demand in the North American job market (10\%) while the remaining three regions are not paying any attention to this skill in job requirements. Figure 4 summarized the results. The hypothesis H-2 was tested using the Kendall coefficient of concordance $(W)$ and Kappa statistics and the results are reported in Table-II. The hypothesis is accepted based on chi-square value of 29.64 and Kendall coefficient of concordance 0.92 significant at $\mathrm{P}<0.001$. The Kappa statistics also further support the acceptance of hypothesis H-2 
(Kappa coefficient: 0.79, Z: 7.90, P < 0.001). Therefore, we conclude that employers' soft skills requirements, as advertised in job postings of software designer are substantially similar across different cultures of the world.

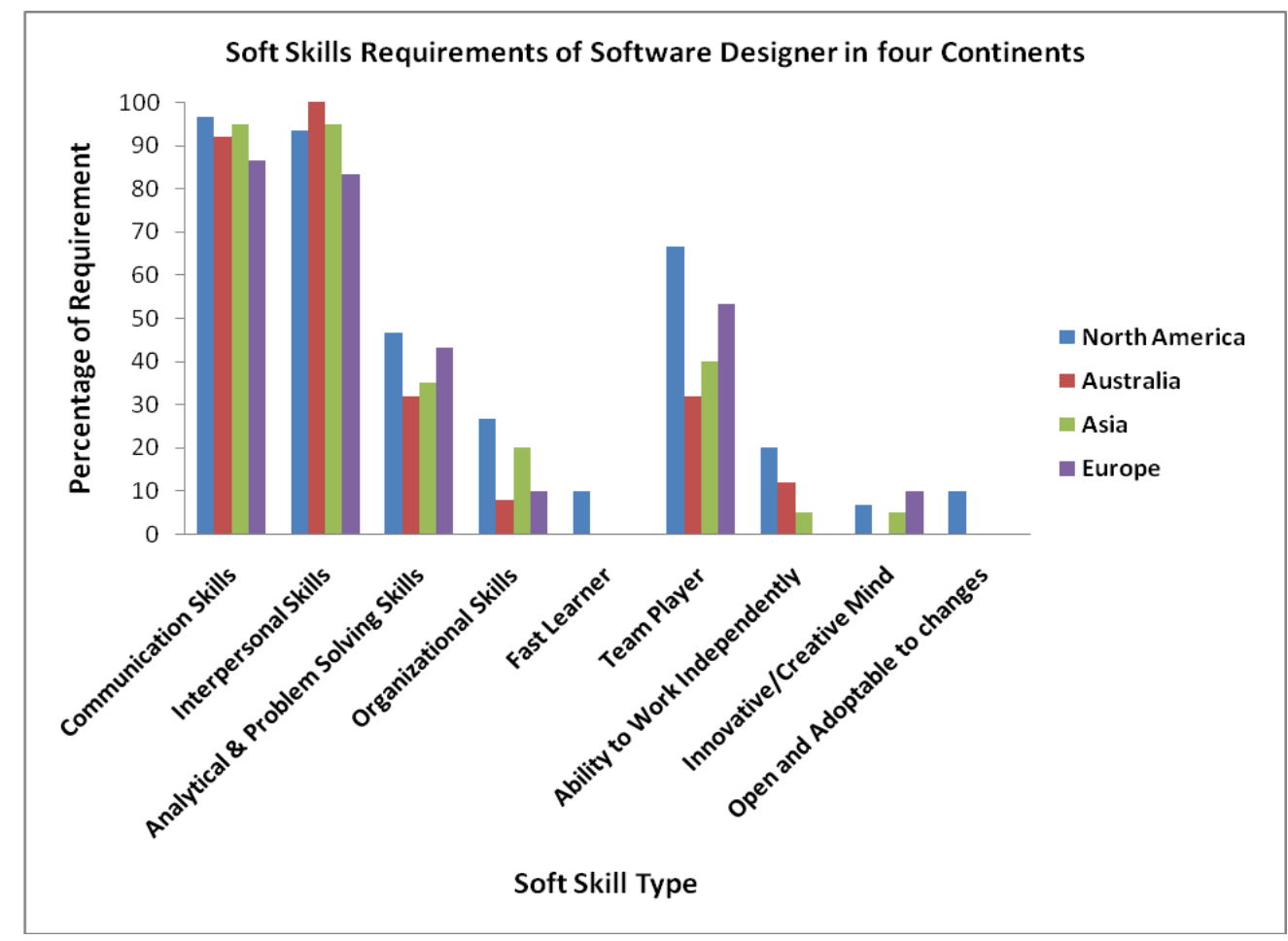

\section{2) Result Discussion}

Figure 4: Soft Skills Qualifications of Software Designer

The descriptive statistics and statistical tests for the significance of hypothesis $\mathrm{H}-2$ provides support to conclude the answer of RQ-2, that substantial similarity exists in soft skills requirements as advertised in the job descriptions for software designer across different cultures. The descriptive statistics also show that seven out of nine soft skills have similarity in requirements across different cultures. Software design is an exploratory process: the designer looks for components by trying out a variety of schemes in order to discover the most natural and reasonable way to refine the solution (Budgen 2003). The analysis shows that the North American job market considers communication, interpersonal, and team player skills high in demand while analytical and problem solving skills are in moderate demand. Conversely the ability to work independently, open and adoptable to changes and organizational skills, fast learner and innovative and creative mind are in low demand in the North American market. The Australian job market requires communication and interpersonal skills in high demand whereas analytical and problem solving skills, team player, ability to work independently, open and adoptable to changes, organizational skills, fast learner and innovative and creative mind are 
in low demand. The Asian job market weights communication and interpersonal skills to be in high demand while analytical and problem solving and team player skills are in moderate demand. Fast learner, organizational skills, innovative and creative mind, ability to work independently, and open and adoptable to changes skills are in low demand in the Asian software industry. In the case of European software industry communication and interpersonal skills are in high demand and team player and analytical and problem solving skills are in moderate demand. Whereas fast learner and innovative and creative mind, ability to work independently, and open and adoptable to changes, and organizational skills, are in low demand.

\section{Software Programmer}

\section{1) Descriptive Statistics \& Hypothesis Testing}

We collected data from 140 job descriptions for computer programmers from the software job market and analysis shows that in the case of communication skills all four geographical regions of this study exhibit a high demand such as North America (88\%), Europe (91\%), Asia (85\%) and Australia (96\%). In case of interpersonal skills two geographical regions of this study also show a high demand, Australia (80\%) and Asia (71\%) while North America (62\%) and Europe (54\%) demonstrated a moderate demand. Analytical and problem solving skills are in moderate demand in North America (62\%), Asia (51\%), Europe (54\%) and Australia (36\%). Organizational skills are in moderate demand in the three geographical regions of North America (48\%), Europe (34\%) and Asia (40\%) and are in low demand in case of Australia (20\%). The skill of fast learner not being given much attention in any of the four geographical regions and is in low demand, North America (4\%), Europe (5\%), Asia (2\%) and Australia (0\%). Team player skills are in high demand in North America (80\%) only, whereas in the case of Europe (60\%), Asia (42\%), and Australia (64\%) it is in moderate demand. The skill to work independently is in moderate demand in the case of North America (51\%), and is in low demand in the remaining three regions of Australia (20\%), Asia (25\%) and Europe (28\%). Innovative and creative thinking ability is in low demand at North America (17\%), Europe (20\%), Australia (4\%), and Asia (2\%). Open and adoptable to changes is only low in demand in the North American (6\%) and the European (2\%) job market whereas the remaining two regions are not paying any attention to this skill in job requirements. Figure 5 summarizes the survey results. The hypothesis H-3 was tested using the Kendall coefficient of concordance $(W)$ and Kappa statistics and the results are reported in Table-II. The hypothesis is accepted based on chi-square value of 18.35 and Kendall coefficient of concordance 0.57 significant at $\mathrm{P}<0.01$. The Kappa statistics also further support the acceptance of hypothesis H-3 
(Kappa coefficient: 0.62, Z: 6.23, P < 0.001). Therefore, we conclude that employers' soft skills requirements, as advertised in job postings of computer programmer are substantially similar across different cultures of the world.

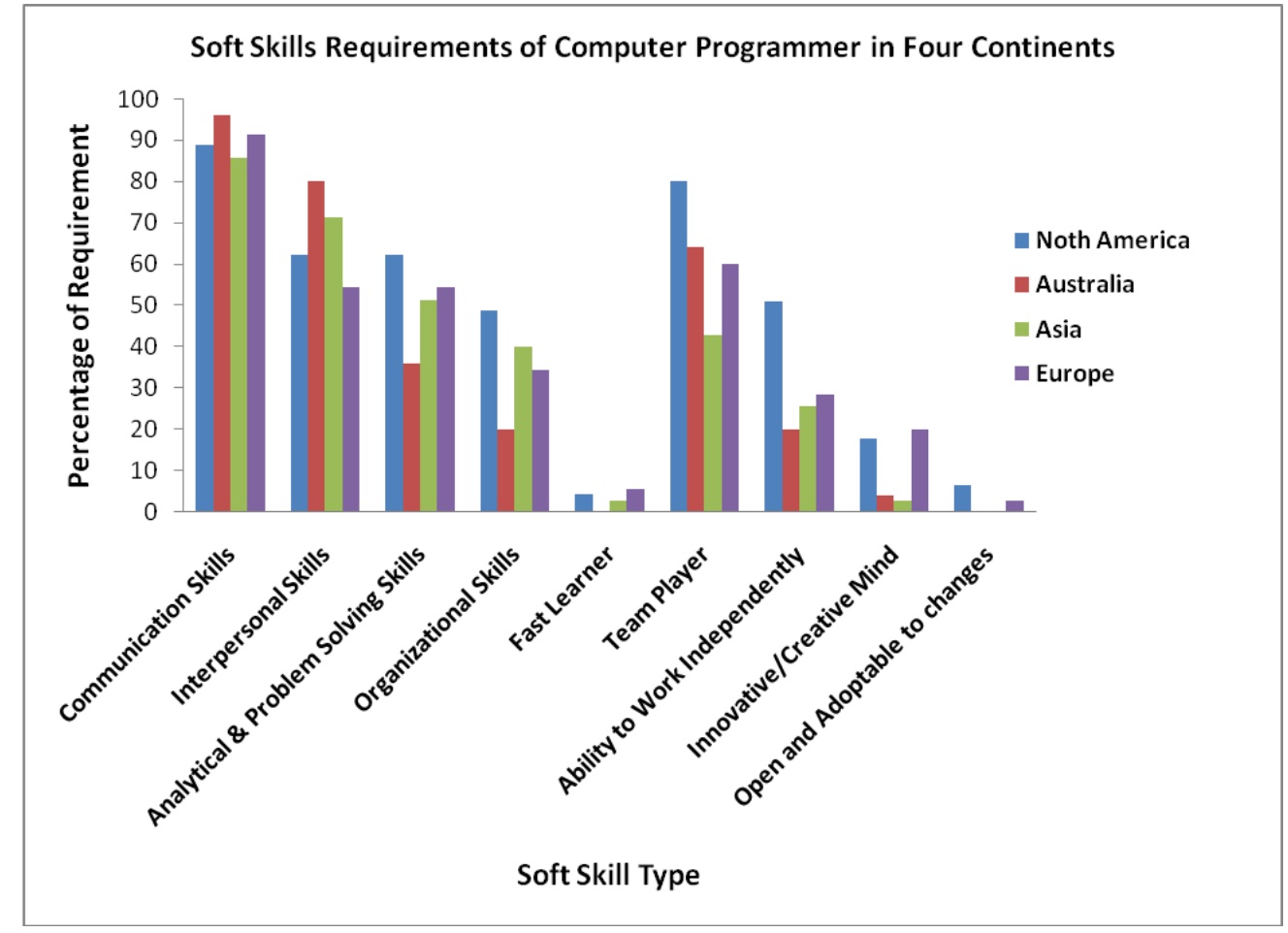

Figure 5: Soft Skills Desirable for a Computer Programmer

\section{2) Result Discussion}

The descriptive statistics and statistical tests for the significance of hypothesis $\mathrm{H}-3$ provides us with support to conclude that the answer of RQ-3 is that there exists a substantial similarity in soft skills requirements as advertised in the job descriptions of computer programmer across different cultures. The descriptive statistics also show that five out of nine soft skills have similarity in requirements across different cultures. The simplest definition of a programmer's job is translating a refined version of the design into a computer executable program (Weinberg 1971). The broader technical aspects of this phase requires the identification of control structures, relevant variables and data structures, and a detailed understanding of the syntax and specifics of a given programming language. The analysis shows that North American job market only considers communication and team player skills high in demand whereas interpersonal skills, analytical and problem solving, ability to work independently and organizational skills are in moderate demand. By contrast, open and adoptable to change, fast learner, innovative and creative mind are in low demand in the North American market. The Australian job market requires communication and interpersonal skills in high demand whereas analytical and problem solving and team player skills are in moderate demand. The ability to work independently, 
open and adoptable to changes, organizational skills, fast learner and innovative and creative mind are in low demand. The Asian job market weights communication and interpersonal skills in high demand while analytical and problem solving, team player and organizational skills are in moderate demand. Fast learner, innovative and creative mind, ability to work independently, and open and adoptable to changes skills are in low demand in the Asian software industry. In case of European software industry only communication skills are in high demand whereas team player, analytical and problem solving and interpersonal, organizational skills are in moderate demand. In addition it was found that fast learner and innovative and creative mind, ability to work independently, and open and adoptable to changes, are in low demand.

\section{Software Tester}

\section{1) Descriptive Statistics \& Hypothesis Testing}

We collected the data of 140 job descriptions for software testers advertised in the software job market and analysis shows that in the case of communication skills all four geographical regions of this study show a high demand, such as North America (76\%), Europe (80\%), Asia (82\%) and Australia (75\%). In case of interpersonal skills all four geographical regions of this study exhibit a low demand, such as North America (21\%), Europe (28\%), Asia (25\%) and Australia (13\%). Analytical and problem solving skills are in moderate demand in North America (60\%), Europe (52\%) and Australia $(36 \%)$ while in low demand in the case of Asia (20\%). Organizational skills are in moderate demand in two geographical regions of North America (47\%), and Australia (38\%) whereas in the cases of Europe (32\%) and Asia (22\%) it is in low demand. The skill of being fast learner is not given much attention in any of the four geographical regions and is in low demand, North America (6\%), Europe $(8 \%)$, Asia (0\%) and Australia (2\%). Team player skills are in moderate demand in North America $(39 \%)$ only, while in cases of Europe (32\%), and Asia (11\%), and Australia (25\%) it is in low demand. The skill to work independently is in low demand in all four regions, North America (19\%), Australia $(30 \%)$, Asia (2\%) and Europe (16\%). Innovative and creative thinking ability is in low demand in North America (8\%), Europe (12\%), Australia (0\%), and Asia (5\%). Open and adoptable to changes is low in demand in North America (2\%), Europe (12\%), Asia (0\%) and Australia (8\%). Figure 6 summarizes the survey results. The hypothesis H-4 was tested using the Kendall coefficient of concordance $(W)$ and Kappa statistics and the results are reported in Table II. The hypothesis is accepted based on chi-square value of 26.62 and Kendall coefficient of concordance 0.83 significant at $\mathrm{P}<0.001$. The Kappa statistics also further supports the acceptance of hypothesis H-4 (Kappa 
coefficient: $0.68, \mathrm{Z}: 6.57, \mathrm{P}<0.001)$. Therefore, we conclude that employers' soft skills requirements, as advertised in job postings of software tester are substantially similar across different cultures of the world.

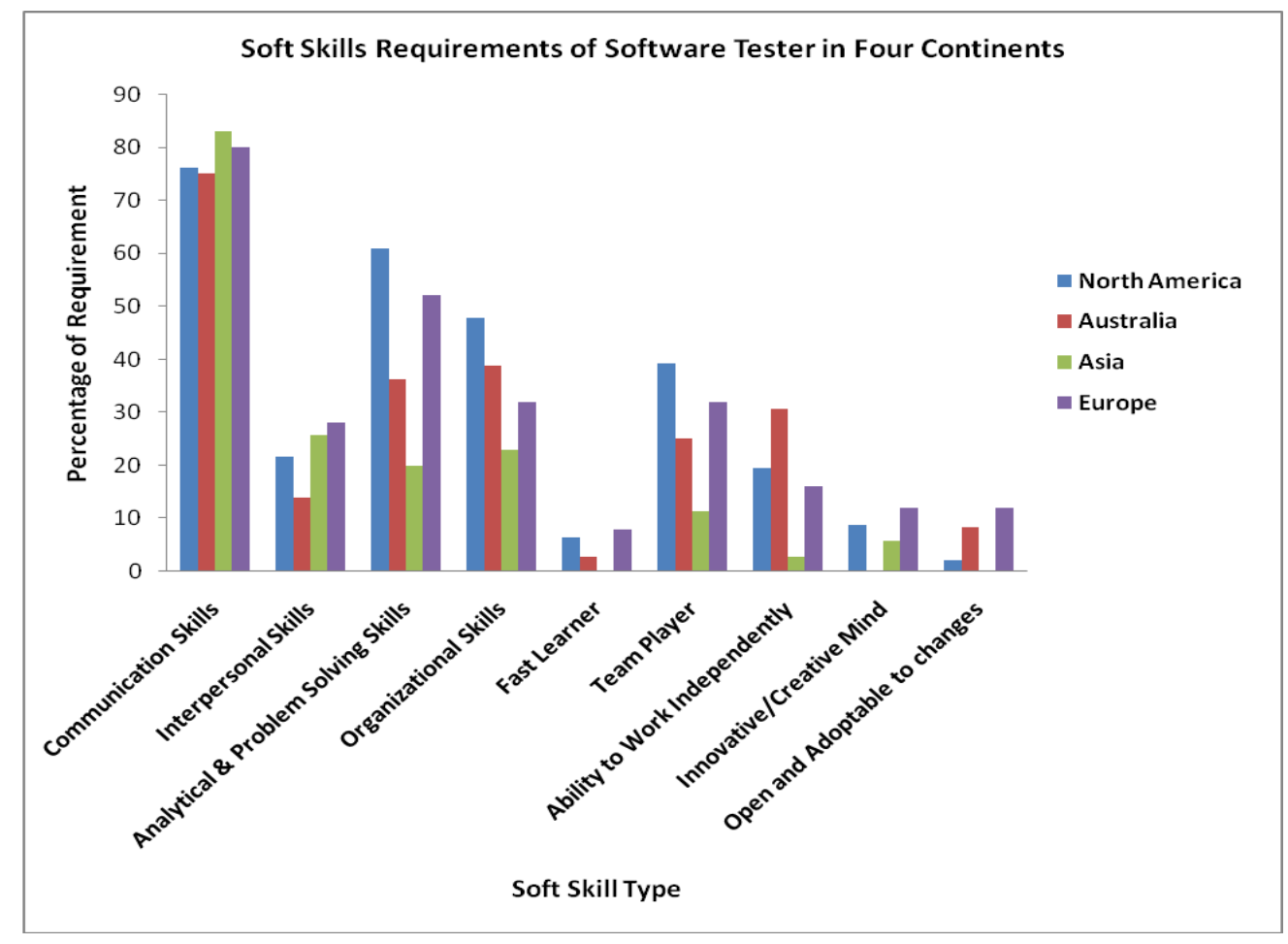

\section{2) Result Discussion}

Figure 6: Soft Skills Desirable for a Software Tester

The descriptive statistics and statistical tests for the significance of hypothesis $\mathrm{H}-4$ provides us with support to conclude that the answer of RQ-4 is that substantial similarity exists in the soft skills requirements as advertised in the job descriptions of software tester across different cultures. The descriptive statistics also show that six out of nine soft skills have similarity in requirements across different cultures. Software testers are considered as the worst enemies in the software development team because they are the group who carries the bad news of defects, which requires good communication and interpersonal skills to keep the team active and avoid conflicts (Whittaker 2000). The analysis revealed that the North American job market only considers communication skills high in demand whereas and team player, analytical and problem solving, and organizational skills are in moderate demand. By contrast, interpersonal skills open and adoptable to changes, ability to work independently, fast learner and having innovative and creative mind are in low demand in the North American market. The Australian job market also requires only communication skills in high demand whereas analytical and problem solving organizational skills are in moderate demand. Ability to work 
independently, interpersonal, open and adoptable to changes, team player, fast learner and having innovative and creative mind are in low demand. The Asian job market also weights only communication skills in high demand whereas analytical and problem solving, organizational, fast learner, team player, innovative and creative mind, interpersonal ability to work independently, and open and adoptable to changes skills are all in low demand in the Asian software industry. In the case of European software industry only communication skills are in high demand while analytical and problem solving skills are in moderate demand. On the other hand team player, interpersonal, organizational, fast learner and innovative and creative mind, ability to work independently, and open and adoptable to changes, are in low demand.

\section{Limitations OF the Study \& ThreatS to EXTERnAL VALIDITY}

All empirical investigations and surveys are subject to certain limitations and there are always threats to external validity. This is equally true is the case of this study. The following section highlights some of the limitations of this study:

- The first limitation is the selection and participating soft skills variables of the study. In this study we collected data concerning nine soft skills which include communication skills, interpersonal skills, analytical and problem solving skills, team player, organizational skills, ability to work independently, innovative and creative mind, fast learner and open and adaptable to changes. We found these nine soft skills to be the most commonly used in the advertisement of the jobs. In addition to the selected nine skills there may be other soft skills that influence the performance of software development which have not been included in this study.

- Some other contributing factors to performance of software development, such as: organization size, economic, experience in software development and political conditions were not considered in this study because we chose to investigate solely the impact of soft skills.

- There are some limitations of this study related to data collection. We collected data from four regions of the world, i.e. North America, Europe, Asia and Australia. This geographical diversity reduces the threats to external validity, however as we used only one source of data collection i.e. online job portals from each region, this may pose a potential threat to external validity. Conversely, the section of these job portals for data collection was primarily based on the popularity of these websites amongst job seekers and employers and the volume of data 
posted.

- Similarly, we collected data about four different roles and their related titles but there may be other denominations of these roles, as well as other types of role in software development which are not considered in this study.

- When we visited each job page we selected a job for inclusion in the dataset only if we found at least one of the nine soft skills under investigation in job description. We did not retain a record of those job advertisements that were visited but which did not specifically list a requirement for at least one of the soft skills under investigation in this study.

- No specific consideration was given to the selection of timing for the data collection the choice was simply random.

- In this study we collected the data from online job portals and after analysis we reported the results. We did not do any further investigation, e.g. who was interviewed, what questions were asked, who got the job, etc.

\section{Conclusion}

Software engineering is a global enterprise with development teams composed of individuals from a variety of countries and cultural backgrounds. The dynamics of how these diverse individuals operate within the development team is an issue that has been generally ignored by researchers and professionals. Soft skills are usually overlooked in software engineering because the relationship between software engineering and soft skills is extremely complex to investigate. Nevertheless, it has been worthwhile studying which soft skills are required by the software industry and which are overlooked and how the dynamics of this relationship works across different cultures. This survey provides vital information in the form of descriptive statistics about soft skills requirements in different regions of the world. We concluded the answer of the research question (RQ) of this study that in the cases of designer, programmer and tester substantial similarity exits in the requirements of soft skills whereas only in the case of system analyst dissimilarity present across different cultures.

\section{References}

Acuna ST, Juristo N, Moreno A M (2006): Emphasizing human capabilities in software development. IEEE Software 23(2): 94-101.

Altman D (1991) Practical statistics for medical research. Chapman and Hall.

Beard D, Schwieger D, Surendran K (2009) Integrating soft skills assessment through university, college, and 
programmatic efforts at an AACSB Accredited Institution. Journal of Information Systems Education 19(2): 229-240.

Behm C A (2003). People skills: The core of performance improvement. International Performance Improvement Networker Newsletter 19(7): 1-11.

Bishop-Clark C (1995) Cognitive style, personality, and computer programming. Computers in Human Behaviour 11(2): 241-260.

Bolton R (1986) People skills, Touchstone Books, New York

Buchanan T, Johnson J A, Goldberg L R (2005): Implementing a five-factor personality inventory for use on the internet. European Journal of Psychological Assessment 21(2): 116-128.

Budgen D (2003) Software design, Addison Wesley

Byrd T A, Turner D E (2004) An exploratory analysis of the value of the skills of IT personnel: their relationship to IS infrastructure and competitive advantage. Decision Sciences 32(1): 21-54.

Cappel J (2002) Entry-level IS job skills: a survey of employers. Journal of Computer Information Systems. 42(2): 76-82.

Capretz L F (2003) Personality types in software engineering. International Journal of Human-Computer Studies 58(2): 207-214.

Capretz L F, Ahmed F (2010) Making sense of software development and personality types. IEEE IT Professional 12(1): 6-13.

Cohen J (1960) A coefficient of agreement for nominal scales. Educational and Psychological Measurement 20: $37-46$.

Dash J 0(2001) Schools push soft skills for info security majors. Computerworld 35(6): 24.

DeSouza C R B, Sharp H, Singer J, Cheng L, Venolia G (2009) Cooperative and human aspects of software engineering. IEEE Software 26(6): 17-19.

Ein Dor P, Segev E, Orgad M (1992). The effect of national culture on IS: implications for international information systems. Journal of Global Information Management 1(1): 33-44.

Faure G O, Rubin J Z (1993). Culture and negotiation: the resolution of water disputes, Sage Publications.

Feldt R, Torkar R, Angelis L, Samuelsson M (2008) Towards individualized software engineering: empirical studies should collect psychometrics. In: Proceedings of Workshop on Cooperative and Human Aspect of Software Engineering (CHASE), pp. 49-52.

Fiske A P, Kitayama S, Markus H R, Nisbett R E (1998) The cultural matrix of social psychology. In Gilbert D T, Fiske S T, Lindzay G (Eds.) Handbook of Social Psychology (915-981). Boston, MA: McGraw Hill

Fleiss J (1981) Statistical methods for rates and proportions. John Wiley \& Sons

Goldberg L R (1990) An alternative description of personality: The big-five factor structure. Journal of Personality and Social Psychology 59: 1216-1229. 
Goleman D (1998) Working with emotional intelligence. Bantam, NY

Goleman D (1995) Emotional intelligence, Bantam Books, NY

Gorman H (2000). Winning hearts and minds? emotional labour and learning for care management. Journal of Social Work Practice 14(2): 149-158.

Green G L (1989) Perceived importance of systems analysis job skills, roles, and non-salary incentives. MIS Quarterly 13(2): 115-133.

Hall E T (1960) The silent language in overseas business, Harvard Business Review

Hannay J E, Arisholm E, Engvik H, Sjoberg D I K (2010) Effects of personality on pair programming. IEEE Transactions on Software Engineering 36(1): 61-80.

Hardiman L T (1997) Personality types and software engineers. IEEE Computer 30(10): 10.

Harrison W L, Farn C K (1990) A comparison of information management issues in the United States of America and the Republic of China. Information \& Management 18(4): 177-188.

Hayes J (2002) Interpersonal skills at work. Taylor \& Francis.

Hofstede G (1994) Cultures and organizations: software of the mind intercultural cooperation and its importance for survival. HarperCollins Publishers, London.

Isaacs N (1998) Use job interviews to evaluate soft skills. InfoWorld 20(14): 104.

Kaluzniacky E (2004) Managing psychological factors in information systems work, Information Science Publishing, London.

Karn J S, Cowling A J (2005) Using ethnographic methods to carry out human factors research in software engineering. Behavior Research Methods 38(3): 495-503.

Kendall P A (1992) Introduction to systems analysis and design: a structured approach, Brown Publishers

Khan M B, Kukalis S (1990) MIS professionals: education and performance. Information and Management 19: 249-255.

Kushal S.J, Ahuja S (2009) Business communication, V.K. Enterprises.

Landis J, Koch G G (1977) The measurement of observer agreement for categorical data. Biometrics 33: 159174.

Lau S K, Trauth E M, Farwell D W (1997) Information systems skills: a comparison of perceptions between information systems professionals from indonesian and malaysian organizations. Journal of Computer Information Systems 27(3): 60-68.

Legendre P (2005) Species associations: the kendall coefficient of concordance revisited, Journal of Agricultural, Biological and Environmental Statistics 10: 226-245

Leitheiser R L (1992) MIS skills for the 1990s: a survey of MIS managers' perceptions. Journal of Management Information Systems 9(1): 69-91.

Lewis T L, Smith W J, Bélanger F, Harrington K V (2008) Are technical and soft skills required? In: 
Proceedings of 4th Workshop on Computing Education Research, pp. 91-100.

Litecky C R, Arnett K P, Prabhakar B K (2004) The paradox of soft skills versus technical skills in hiring. Journal of Computer Information Systems 45 (1): 69-76.

McGee M (1996) Soft skills can boost careers. Informationweek 84.

Olson J S, Olson G M (2003) Culture surprises in remote software development teams. ACM Queue 1(9): 5259.

Parcon P (2007) Develop your team building skills. Lotus Press.

Parkinson M (2008) How to master psychometric tests. Kogan Page.

Roan A, Whitehouse G (2007) Women, information technology and waves of optimism: australian evidence on mixed-skill jobs. Work and Employment 22 (1): 21-33.

Russell M T, Karol D L (1994) 16PF Administrator's manual, Institute for Personality and Ability Testing, Fifth Edition.

Samovar L A, Porter R E (1995) Communication between cultures, 4th Ed. Wadsworth Publishing

Schulz Y (1998) New world puts emphasis on softer skills. Computing Canada 24(45): 21-22.

Shneiderman D (1980) Software psychology: human factors in computer and information systems. Cambridge, MA, Winthrop Publishers

Shore B, Venkatachalam A (1995) The role of national culture in systems analysis and design. Journal of Global Information Systems Management 3(3): 5-14.

Singer J, Vinson N G (2002) Ethical issues in empirical studies of software engineering. IEEE Transactions on Software Engineering 28(12): 1171-1180.

Stolte H, Munjanganja E (2008) Final Report, International Conference Corporate HRD and Skills Development for Employment: Scope and Strategies, Available at:

http://www.unevoc.unesco.org/fileadmin/user_upload/pubs/Corporate_HRD_and_Skills_Development_for_Em ployment_Scope_and_Strategies.pdf

Teague G J (1998) Personality type, career preference and implications for computer science recruitment and teaching. In: Proceedings of 3rd Australian Conference on Computer Science Education, pp. 155-163.

Tech Directors, (2003) Career Directions 10: 22-23

Trauth E M, Farwell D W, Lee D (1993) The IS expectation gap: industry expectations versus academic preparation. MIS Quarterly 17(3): 293-307.

Turley E A, Bieman J M (1995) Competencies of exceptional and non-exceptional software engineers. Journal of Systems and Software 28(1): 19-38.

Unnikrishnan R, Hebert M (2005) Measures of similarity. In: Proceedings of IEEE Workshop on Applications of Computer Vision, pp. 394-400.

van Slyke C, Kittner M, Cheney P (1998) Skill requirements for entry-level IS graduates: a report from Industry. Journal of Information Systems Education 9(3): 7-11. 
von Eye A, Mun E Y (2005) Analyzing rater agreement manifest variable methods. LEA Publishers, London Wade M, Parent M (2001) Relationships between job skills and performance: a study of webmasters. Journal of Management Information Systems 18(3): 71-96.

Walz D B, Wynekoop J L (1997) Identifying and cultivating exceptional software developers. Journal of Computer Information Systems 37(4): 82-87.

Weinberg G M (1971) The psychology of computer programming. Van Nostrand Reinhold, New York

Whittaker J A (2000) What is software testing? and why is it so hard. IEEE Software 17(1): 70-79.

Wynekoop J L, Walz D B (2000) Traits of top performing software developers. Information Technology and People 13: 186-195.

Young D, Lee S (1996) The relative importance of technical and interpersonal skills for new information systems personnel. Journal of Computer Information Systems 36: 66-71. 